\title{
Maintenance of the spinal nucleus of bulbocavernosus and perineal muscles in female Albino Swiss rats treated with perinatal dihydrotestosterone*
}

\author{
T. Davidson, A. M. Tobin and A. P. Payne \\ Department of Anatomy, University of Glasgow, Glasgow G12 8QQ, UK
}

\begin{abstract}
Summary. Female Albino Swiss rats were exposed to $5 \alpha$-dihydrotestosterone benzoate (DHTB) for the last 4 days of gestation, or for 4 days after birth, or both. Post-natal DHTB exposure (as well as pre- plus post-natal exposure) resulted in a 2-3-fold increase in the number of motor neurones forming the spinal nucleus of bulbocavernosus (SNB); numbers were intermediate between those found in normal females $(\sim 40)$ and males $(\sim 200)$. These DHTB-treated groups also possessed perineal muscles which were $\sim 25 \%$ of the weight of those in normal males. Transverse sections of one of the muscles (levator ani) showed that it had approximately half the muscle fibres of normal males. Females exposed prenatally to DHTB showed a small (but significant) rise in SNB numbers, but had no recognizable perineal muscles.
\end{abstract}

Keywords: neonate; motor neurones; hormones: perineal muscles; rat

\section{Introduction}

Several regions of the mammalian central nervous system exhibit morphological sex differences in size, in neurone populations or in the types of synaptic connection occurring within them. These differences are established during the perinatal period and depend on the hormone environment at that time (Arnold \& Gorski, 1984; Sengelaub, 1989). Within the lower lumbar/upper sacral region of the rat spinal cord is a dimorphic group of motor neurones, the spinal nucleus of bulbocavernosus (SNB), which innervates perineal muscles implicated in penile erection and genital reflexes associated with cervical stimulation and copulatory plug formation (Breedlove \& Arnold, 1981; Breedlove, 1984). This group of motor neurones may be the counterpart of Onuf's nucleus in man and dogs (Forger \& Breedlove, 1986). In adult rats, the SNB in males contains some 5 times more neurones than does the SNB in females. Moreover, adult female rats lack perineal muscles which are conspicuous in the male; they are said to involute soon after birth unless androgens are present (Cihák et al., 1970; Arnold, 1984).

Development of the SNB in rats could form an important model for the role of hormones in neurogenesis, cell death and migration (Sengelaub, 1989). However, in mice it is known that there are strain differences in SNB numbers (Wee \& Clemens, 1986) and in their responsiveness to hormone manipulation outside the perinatal period (Wee \& Clemens, 1987). Similar strain differences may occur in other laboratory species. For example, pre- or post-natal exposure to testosterone maintains the SNB complex in Sprague-Dawley rats, while dihydrotestosterone is less effective (and is only effective when administered post-natally) and oestradiol is without effect (Breedlove $e t$ al., 1982; Hall et al., 1987; Sengelaub et al., 1989). In Albino Swiss rats, post-natal dihydrotestosterone administration is very effective at maintaining SNB neurone numbers, while testosterone and

*Reprint requests to Dr A. P. Payne. 
oestradiol are (a) equipotent and (b) somewhat less effective (Currie et al., 1990). The present experiment was undertaken with Albino Swiss rats to determine in which part of the perinatal period hormones act to preserve SNB neurones (and the perineal muscles which are normally innervated by them) in this strain.

\section{Materials and Methods}

Three experimental groups of female Albino Swiss rats were used. In Group 1, pregnant female rats received injections of dihydrotestosterone benzoate (DHTB, $500 \mu \mathrm{g}$ per day, s.c.) (Sigma Chemical Co. Ltd., Poole. Dorset BH17 $7 \mathrm{NH}, \mathrm{UK})$ on the last 4 days of pregnancy; the female pups born to these mothers then received DHTB $(200 \mu \mathrm{g}$, s.c. $)$ on Days 1-4 after birth $(\mathrm{N}=9)$. Group 2 consisted of pups which received DHTB after birth as above, but had received no pre-natal exposure $(\mathrm{N}=17)$. Group 3 consisted of pups which had been exposed pre-natally as above, but not post-natally $(\mathrm{N}=12)$. All hormones were injected in arachis oil $(0.1 \mathrm{ml})$ and control females $(\mathrm{N}=17)$ received oil vehicle alone. As adults, all females received testosterone propionate for 1 month $(500 \mu \mathrm{g}, 3$ times/week, s.c.) to (i) enhance the size and staining properties (but not the number) of SNB neurones (Arnold, 1984) and (ii) to increase the size of the perineal muscle fibres, thus making the muscles (if present) readily identifiable (Venable, 1966). A group of control males $(\mathrm{N}=17)$ was also examined. All animals were killed with an overdose of pentobarbitone sodium, and perfused with mammalian Ringer with lignocaine followed by $500 \mathrm{ml}$ buffered $10 \%$ formaldehyde. The perineal muscles, if present, were dissected out and weighed, together with the phallus. The lower part of the spinal cord was removed and stored in buffered $10 \%$ formaldehyde before sectioning at $100 \mu \mathrm{m}$ on a Bio-rad micro-cut $\mathrm{H} 1200$ vibratome and staining with $0.4 \%$ thionine in alcohol and acetic acid $(\mathrm{pH} 4.5)$. All sections with SNB neurones were examined and the number of neurones counted. Only those neurones in which a nucleolus could be seen were included, and no correction for cell size was made. One of the perineal muscles, the levator ani, was used for a count of individual muscle fibres in control males $(\mathrm{N}=5)$, females given post-natal DHTB $(\mathrm{N}=8)$ and females given pre- and post-natal DHTB $(\mathrm{N}=9)$. This muscle (considered by many to be a dorsal component of bulbocavernosus, e.g. Hayes, 1965; McKenna \& Nadelhaft, 1986) was chosen because individual fibres run the whole length of each side of the muscle from its origin to a fibrous midline raphe (Venable, 1966); hence, a single suitably placed transverse section will allow all fibres to be counted. Each levator ani was pinned out flat on cork and stored immersed in buffered $10 \%$ formaldehyde before processing for routine histology and staining with haematoxylin and eosin.

SNB neurone counts, perineal muscle weights and levator ani fibre counts were compared for the groups using one-way analyses of variance (F) followed by Least Significant Difference analysis (Statistical Graphics System; Statistical Graphics Corporation) to reveal inter-group differences.

\section{Results}

Analysis of variance of the results in Table 1 revealed a significant variance over the 5 groups (F $=71 \cdot 35$, df $4 \times 69, P<0 \cdot 001)$. All three experimental DHTB-treated groups had significantly more SNB neurones than did control females (for all, $P<0.01$ ), but significantly fewer SNB neurones than control males (for all, $P<0 \cdot 01$ ). Females treated only pre-natally with DHTB differed from the other two experimental groups $(P<0.01)$; this particular group consisted of a minority of females with SNB counts of over 100 and a majority with counts of 50-70 (see Fig. 1). Those females with high counts were all from one litter, although not all females from this litter had high counts.

No morphologically identifiable perineal muscles could be found in control female rats, nor in those which had received DHTB pre-natally only (even if they had high SNB neurone counts). By contrast, females which had received post-natal DHTB, or females which had received both preand post-natal DHTB, had obvious muscle complexes. These were about $25 \%$ of the weight of the muscle complex in normal males. There was a significant variance between the muscle weights of the three groups which possessed them $(\mathrm{F}=64.3$, df $2 \times 25, P<0.001)$, and the DHTB-treated females had significantly smaller muscles than control males (both groups of females differed from males, $P<0.01$ ). Similarly, there was a significant variance between these three groups for the number of muscle fibres in the levator ani ( $\mathrm{F}=3.79$, df $2 \times 25, P<0.05$ ), with DHTB-treated females having only about half the number found in control males (both groups of females differ from males, $P<0.05$ ). 
Table 1. The number of SNB motor neurones and the weight of the perineal muscle complex $(\mathrm{g} / 100 \mathrm{~g}$ body weight) in female Albino Swiss rats which had received exposure to dihydrotestosterone benzoate (DHTB) pre-natally, postnatally or both

\begin{tabular}{lrccc}
\hline & $\begin{array}{c}\text { No. of } \\
\text { rats }\end{array}$ & $\begin{array}{c}\text { SNB } \\
\text { numbers }\end{array}$ & $\begin{array}{c}\text { Weight of } \\
\text { perineal muscles } \\
(\mathrm{g} / 100 \mathrm{~g})\end{array}$ & $\begin{array}{c}\text { Fibres in } \\
\text { levator ani }\end{array}$ \\
\hline $\begin{array}{l}\text { Perinatal treatment } \\
\quad \text { control females }\end{array}$ & 17 & $38 \pm 3$ & absent & - \\
Pre-natal DHTB & 12 & $79 \pm 10$ & absent & - \\
Post-natal DHTB & 17 & $131 \pm 11$ & $0 \cdot 17 \pm 0 \cdot 01$ & $2297 \pm 144$ \\
Pre- and post-natal DHTB & 9 & $116 \pm 8$ & $0 \cdot 14 \pm 0 \cdot 01$ & $2318 \pm 280$ \\
Control males & 17 & $218 \pm 24$ & $0 \cdot 51 \pm 0 \cdot 04$ & $3940 \pm 973$ \\
\hline
\end{tabular}

Values are mean \pm s.e.m.

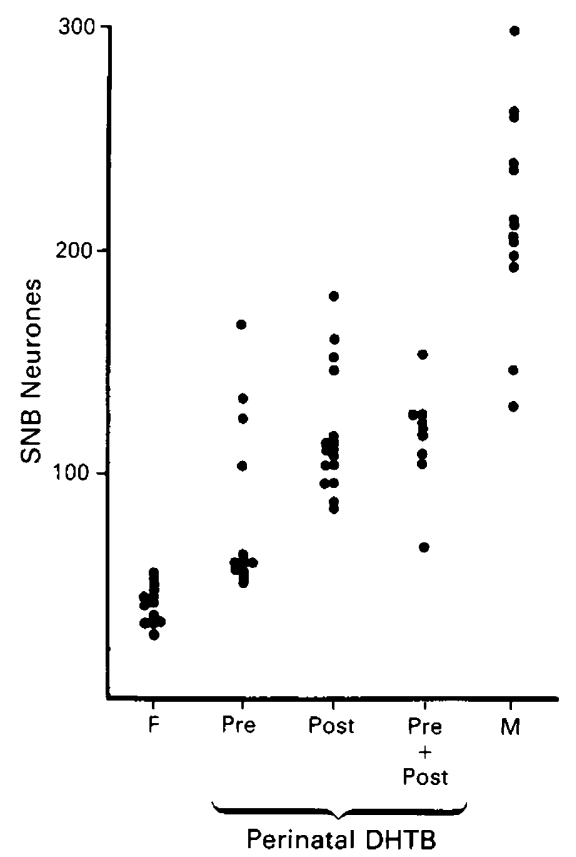

Fig. 1. The number of SNB motor neurones in control female (F) and male (M) Albino Swiss rats, and in females which had received $5 \alpha$-dihydrotestosterone benzoate (DHTB) pre-natally (Pre), post-natally (Post) or both.

\section{Discussion}

The present experiment confirms that a structural sex difference occurs in the lumbosacral part of the rat spinal cord. Thus, normal adult males possess some 200 motor neurones which form the spinal nucleus of bulbocavernosus (SNB), while females have approximately $20 \%$ of this number. The present experiments also confirm that the administration of androgens to females during the perinatal period results in the maintenance of higher numbers of SNB neurones than in control females. Currie et al. (1990) have demonstrated that $5 \alpha$-dihydrotestosterone was effective in maintaining SNB neurones in Albino Swiss rats, although sexual dimorphisms within the brain appear 
to require aromatizable androgens for masculinization (e.g. Arnold \& Gorski, 1984; Tobet et al., 1986).

Previous studies with Sprague-Dawley rats suggest that pre-natal DHT administration cannot maintain SNB numbers (e.g. Breedlove \& Arnold, 1983; Arnold, 1984) while post-natal administration can (e.g. Sengelaub et al., 1989); the reverse may be true for testosterone administration (Arnold \& Gorski, 1984). When both hormones have been effective, DHT has not been as effective as testosterone (e.g. Arnold \& Gorski, 1984). In the present study (involving Albino Swiss rats), while no steroid treatment given to females was able to raise SNB neurone numbers to male levels, post-natal administration of DHT (or a combination of pre- and post-natal administration) resulted in numbers $2-3$ times higher than in normal females. Pre-natal DHTB administration had a variable effect, maintaining SNB neurone numbers at a higher level in some individuals than in others. Pre-natal DHT administration to female Sprague-Dawley rats may maintain perineal muscles without SNB neurones (Sengelaub et al., 1989), a finding at variance with the results obtained here.

In male rats, the majority of SNB neurones (also termed dorsomedial neurones, e.g. Schrøder, 1980) innervate the perineal muscles bulbocavernosus and levator ani; the latter has also been described as a dorsal component of bulbocavernosus (Hayes, 1965; McKenna \& Nadelhaft, 1986) or an external anal sphincter (Cihák et al., 1967, 1970)). A minority of SNB neurones, and the small number of SNB neurones still present in adult females, innervate the anal sphincter (Schrøder, 1980; McKenna \& Nadelhaft, 1986). While perineal muscles develop initially in both sexes, in females they involute after birth (Cihák et al., 1970); morphologically detectable perineal muscles do not occur in adult females and androgen administration to adult female rats cannot reinstate them (Hayes, 1965). The present experiment confirms previous reports (Arnold, 1984) that perinatal androgen administration can maintain the perineal muscles as well as the SNB neurones which innervate them. In the present experiment, DHTB-treated females treated post-natally and pre- and post-natally possessed readily identifiable perineal muscles; females treated with DHTB during the pre-natal period only did not possess these muscles (see Sengelaub et al., 1989). In those experimental females which possessed them, the muscles were not as large as in normal males and consisted of a smaller number of individual muscle fibres. The finding that females treated pre-natally with DHTB could have raised numbers of SNB neurones without identifiable perineal muscles is of interest since it has been suggested (e.g. Breedlove, 1986) that hormones act on this system primarily by maintaining perineal muscles and that the effect on neurone survival is an indirect consequence. In a previous study with Albino Swiss rats (Currie et al., 1990), post-natal oestradiol treatment maintained SNB neurone numbers in the absence of perineal muscles. However, retrograde labelling studies are still needed for Albino Swiss rats in order to confirm which motor neurones innervate particular perineal muscles.

The experiments performed here demonstrate that Albino Swiss rats resemble Sprague-Dawley rats in exhibiting sexual dimorphism in SNB neurone numbers and in the presence or absence of the perineal muscles which are their normal targets. Furthermore, they are similar in their requirement for androgens during the perinatal period to maintain both neurones and muscles. However, the data suggest that there may be differences between strains in the timing of hormone-dependent events and highlight the need to consider possible strain differences in other aspects of this developmental model.

\section{References}

Arnold, A.P. (1984) Androgen regulation of motor neuron size and number. Trends in Neuroscience 7 , 239-242.

Arnold, A.P. \& Gorski, R.A. (1984) Gonadal steroid induction of structural sex differences in the central nervous system. Ann. Rev. Neurosci. 7, 413-442.
Breedlove, S.M. (1984) Steroid influences on the development and function of a neuromuscular system. Prog. Brain Res. 61, 147-170.

Breedlove, S.M. (1986) Absence of androgen accumulation by motoneurons of neonatal rats. Soc. Neurosci. Abstr. 12, 1220. 
Breedlove, S.M. \& Arnold, A.P. (1981) Sexually dimorphic motor nucleus in the rat lumbar spinal cord: response to adult hormone manipulation, absence in androgen-insensitive rats. Brain Res. 225, 297-307.

Breedlove, S.M. \& Arnold, A.P. (1983) Hormonal control of a developing neuromuscular system: II. Sensitive periods for the androgen induced masculinization of the rat spinal nucleus of the bulbocavernosus. $J$. Neurosci. 3, 424-432.

Breedlove, S.M., Jacobson, C.D., Gorski, R.A. \& Arnold, A.P. (1982) Masculinization of the female rat spinal cord following a single neonatal injection of testosterone propionate but not estradiol benzoate. Brain Res. 237, 173-181.

Cihák, R., Gutmann, E. \& Hanzliková, V. (1967) Morphologische, physiologische Merkmale, Entwicklung und Homologie des M. 'Levator' anti der Ratte. Anat. Anz. 120, 492-506.

Cihák, R., Gutmann, E. \& Hanzliková, V. (1970) Involution and hormone-induced persistence of the $\mathbf{M}$. sphincter (levator) ani in female rats. J. Anat. 106, 93- 110.

Currie, J.C., Houston, P.A., Henderson, A. \& Payne, A.P. (1990) Neonatal hormone manipulation and the maintenance of perineal muscles and their motor neurones in Albino Swiss rats. J. Reprod. Fert. 89, 597-603.

Forger, N.G. \& Breedlove, S.M. (1986) Sexual dimorphism in human and canine spinal cord: role of early androgen. Proc. natn. Acad. Sci. USA 83, 7527-7531.

Hall, D.S., Rasmussen, K.M. \& Breedlove, S.M. (1987) Early androgen and estrogen differentially affect adult morphology of sexually dimorphic spinal nucleus. Soc. Neurosci. Abstr. 13, 1519.

Hayes, K.J. (1965) The so/called 'levator ani' of the rat. Acta endocr., Copenh. 48, 337-347.
McKenna, K.E. \& Nadelhaft, I. (1986) The organization of the pudendal nerve in the male and female rat. $J$. comp. Neurol. 248, 532-549.

Schroder, H.D. (1980) Organization of the motoneurons innervating the pelvic muscles of the male rat. $J$. comp. Neurol. 192, 567-587.

Sengelaub, D.R. (1989) Cell generation, migration, death and growth in neural systems mediating social behavior. In Advances in Comparative and Environmental Physiology. 3. Molecular and Cellular Basis of Social Behavior in Vertebrates, pp. 239-267. Ed. J. Balthazart. Springer-Verlag, Berlin.

Sengelaub, D.R., Nordeen, E.J., Nordeen, K.W. \& Arnold, A.P. (1989) Hormonal control of neuron number in sexually dimorphic spinal nuclei of the rat. III. Differential effects of the androgen dihydrotestosterone. $J$. comp. Neurol. 280, 637-644.

Tobet, S.A., Zahniser, D.J. \& Baum, M.J. (1986) Differentiation in male ferrets of a sexually dimorphic nucleus in the preoptic/anterior hypothalamic area requires prenatal estrogen. Neuroendocrinology 44, 299-308.

Venable, J.H. (1966) Morphology of the cells of normal, testosterone-deprived and testosterone-stimulated levator ani muscles. Am. J. Anat. 119, 271-302.

Wee, B.E.F. \& Clemens, L.G. (1986) Strain differences in morphology of the spinal nucleus of the bulbocavernosus (SNB) in mice. Soc. Neurosci. Abstr. 12, 1219.

Wee, B.E.F. \& Clemens, L.G. (1987) Characteristics of the spinal nucleus of bulbocavernosus are influenced by genotype in the house mouse. Brain Res. 424, 305310 .

Received 3 May 1990 